\title{
Suicidal Ideation among the Chinese Elderly and Its Correlates: A Comparison between the Rural and Urban Populations
}

\author{
Jianwen Wei ${ }^{1} \mathbb{D}^{\mathbb{D}}$, Jie Zhang ${ }^{2,3, *(\mathbb{D})}$, Yuping Deng ${ }^{2}$, Long Sun ${ }^{4}(\mathbb{D})$ and Ping Guo ${ }^{5,+}$ \\ 1 School of Sociology, Beijing Normal University, Beijing 100875, China; stanwjw@163.com \\ 2 Central University of Finance and Economics School of Social Development, Beijing 100081, China; \\ dengyuping900522@sina.com \\ 3 State University of New York Buffalo State Department of Sociology, Buffalo, NY 14222, USA \\ 4 Shandong University School of Public Health Center for Suicide Prevention Research, Jinan 250012, China; \\ longsun.sdu@gmail.com \\ 5 China Research Center on Aging, Beijing 100054, China; pingguo89@hotmail.com \\ * Correspondence: zhangj@buffalostate.edu \\ † The co-author Ping Guo passed away in 2015.
}

Received: 27 November 2017; Accepted: 25 February 2018; Published: 28 February 2018

\begin{abstract}
Background: As China is going through a profound aging process, the mental health of the elderly is becoming an issue. As in many other societies, the elderly in China is a population at high risk of suicide; Methods: Data for the study were taken from the Sample Survey of the Aged Population in Urban/Rural China (SSAPUR) accomplished in 2010 by the China Ministry of Civil Affairs. The valid sample for this study was composed of 18,683 individuals, including 9416 urban residents and 9267 rural residents both aged 60 or more years; Results: Logistic regression analyses showed that household income and expenditure, the number of children, chronic diseases, disability of daily living, depression, the frequency of visiting neighbors and having friends or relatives who can help or not had remarkable effects on the suicidal ideation among urban and rural old people. Gender, education, political affiliation, marital status and self-rated health status did not work on the dependent variable. However, some risk factors for suicidal ideation among the Chinese elderly were different between rural and urban regions; Conclusions: We should take different measures when facing the different groups of the elderly.
\end{abstract}

Keywords: the Chinese elderly; depression; suicidal ideation; risk factors; urban-rural comparison

\section{Introduction}

Aging is an increasing problem in China today. According to the data of the Sixth National Population Census in 2010, the number of people aged above 60 years was 177,648,705, accounting for $13.26 \%$ of the total population. It had increased by $2.93 \%$ compared with the proportion in 2000 [1]. In contrast to the developed countries, which became rich before their populations became old, the population of China is going through a profound aging process before it becomes wealthy. Because China has not fully prepared for the aging, the elderly are encountering varieties of challenges, such as suicide [2].

China had the third highest rate of suicide among the elderly in the world and the over-65 age group had the highest rate of completed suicide in China, which reached 44.3-200 per 100,000 [3]. From this perspective, we have enough reasons to believe that the prevalence of suicidal ideation among the Chinese elderly was high, too. As an indicator of potential suicidal attempts and behaviors, suicidal ideation should be well-studied, as well as its influencing factors, which can help us to prevent 
and handle the fatal results of suicide. In this paper, the first question we want to discuss is the prevalence of suicidal ideation among the Chinese elderly and its correlates.

The urban-rural dual system is one of social structural characteristics of China and there exist population differences between cities and countries. Many problems in China must be considered and solved in rural/urban specific ways. When it comes to the suicide rate, the rural elderly contribute much more than the urban elderly. To go much further, the suicide rate among the rural elderly was approximately three to five times higher than that among the urban elderly $[3,4]$. Hence, the second question we want to explore in this paper is the differences of the status quo and correlates of suicidal ideation between the urban and rural elderly.

Suicidal ideation in later life is best understood as a multidimensional event. Based on the literature from the West, we have summarized eight correlates of suicidal ideation for the elderly, namely, demographic characteristics, socio-economic status, marital status, physical health, mental health, influence of major events, religious belief and social interaction.

First, demographic characteristics were the basic information of each one, which would inevitably have some effects on people's suicidal ideation to a certain degree, such as female, old age, etc. [5]. Socio-economic status was another indispensable aspect and many scholars have researched the relationship between socio-economic status and suicidal ideation [6]. Family factors provided the most relevant social context for people, so marital status was one of the evident indicators showing the family background. A variety of studies have testified that the unmarried elderly had a higher prevalence of suicidal ideation than the married. Besides the conjugal bond, the parenthood relation cannot be ignored either. Physical condition and the following functional impairment would increase the suicide rates when people were in later life [7] and people who have suicidal intent were frequently living in poor physical health [8]. Besides physical health, psychological condition was also powerful for predicting suicidal ideation and the well-being of psychological states, which can have negative effects on suicidal ideation [9-11]. Social interaction and social participation were also considered as factors that affect suicidal ideation. Social connectedness was negatively associated with suicidal intent $[12,13]$. What's more, the influence of major events would arouse more or less life stress and appear to be an important factor to explain self-harm behavior [14,15]. Previous research had come to a similar conclusion: religious belief had a relation to mental states and further affects the suicidal ideation of people but the its role was indefinite [16].

The literature on elderly suicidal ideation was limited for the Chinese populations. This study contributes to the literature by adding the significant correlates of Chinese elderly suicidal ideation with a comparison between the rural and urban populations.

\section{Method}

\subsection{Data Sources and Samples}

The data used in this study were taken from the Sample Survey of the Aged Population in Urban/Rural China (SSAPUR), which were conducted by China Research Center on Aging (CRCA) on December, 2010 [17].

The Probability Proportional to Size Sampling was used in the sampling process. First, we randomly selected 20 provinces from thirty-one provinces (including municipalities and autonomous regions) in mainland China. Secondly, we randomly selected four cities (in urban areas) or four counties (in rural areas) from each province. Thirdly, we randomly selected 16 sub-districts from each city and 16 towns from each county. Fourthly, we chose 50 communities from each sub-distribute and 50 villages from each town. If there were not 50 communities or villages, we chose all of them. Finally, we selected 10 families that included a person aged above 60 years old from each community or village. One old person would be interviewed from each of the families. Therefore, we obtained 19,986 samples attending this household survey in total. For detailed information of the data collection design and administration, please refer to an earlier publication in Chinese [17]. 
The data were obtained by questionnaire survey, which was self-administered or assisted by survey staff if needed. The survey place was mostly at the respondent's home. A total number of 19,986 questionnaires were collected. After the data cleaning, the number of valid cases for this research was 18,693 , accounting for $93.53 \%$ of the collected cases.

\subsection{Measurement of Variables}

\subsubsection{Dependent Variable}

In SSAPUR, there were three items to reflect the state of suicidal ideation, including the prevalence of suicidal ideation in the past 5 years, 1 year and 1 month. The question for 1 year ideation was "Have you ever seriously consider killing yourself in last 1 year?" Among the 18,237 people who answered the first question, 878 reported suicidal ideation, accounting for $4.81 \%$. About the same number of respondents answered the second question, with 707 reporting suicidal ideation, accounting for $3.88 \%$. A total number of 18,683 elderly responded to the third question and 518 of them reported suicidal ideation, accounting for $2.77 \%$. Considering the accuracy of suicidal ideation among the elderly, we chose the item for suicidal ideation in the past one month as the dependent variable. This variable is of binary-class, Yes $=1$ and $\mathrm{No}=0$.

\subsubsection{Independent Variables}

In the dimension of demographic characteristics, Gender and Age were basic demographic variables. Gender was a binary variable and Male $=1$ and Female $=0$. The age was a continuous variable.

Socio-economic status was measured by education level and financial situation. The education level was graded into illiteracy, primary school (including Sishu, a kind of old-style private school in China) and junior high school, which was ordered from low to high. Financial situation was graded into sufficient, relatively sufficient, roughly enough, relatively insufficient and insufficient, which was ordered from rich to poor.

CCP membership was judged by a question that "whether he/she was a Chinese Communist Party $(\mathrm{CCP})$ member", and Yes $=1$ and No $=0$.

Family factors were reacted by marital status and the number of children. Marital status was divided into married and not married and Yes $=1$ and $\mathrm{No}=0$. The number of children means the current quantity of children, not including the children who had passed by. This variable was continuous.

Physical condition was evaluated by chronic diseases, self-evaluation of the health and disability of daily living. Whether have chronic diseases was a binary variable and Yes $=1$ and No $=0$. Self-evaluation of the health was an ordinal variable and classified into very unhealthy, unhealthy, average, healthy and very healthy. Disability of daily living was measured by the ADL Scale, which had investigated their ability on eating, dressing, toileting, getting in and out of bed, bathing and walking indoors. The answers of every question were divided into "can do it easily", "can do it with some difficulties" and "absolutely cannot do it". Three answers were separately marked into 1, 2 and 3. We had computed the average marks of the six questions above and the higher the score was, the higher the degree of disability was.

Mental condition was reflected by level of depression that was measured by the Geriatric Depression Scale-15 (GDS-15). This scale was comprised of 15 questions which investigated some feelings and behaviors in the past one week. This scale had been widely used in China. The reliability and validity were also testified in previous studies [18-20]. The answers of each question were divided into yes or no and Yes $=1$ and No $=0$. We had added up all the questions and got the total score; the higher the score is, the more severe the depression is.

Social interaction was estimated from four aspects: whether they participated in social activities, whether they have friends or relatives who can chat with them deeply, whether they have friends or relatives who can give them a hand when they need help and whether they visit neighbors. The former 
three variables were binary and Yes $=1$ and $\mathrm{No}=0$; the answers of the last one were divided into frequently, occasionally and never.

Influence of major events was another factor that may function, measured by whether the respondent has encountered some important events which made great effects on their family in the recent one year, such as natural hazards, diseases, accidents, lawsuits, dispute and land acquisition and Yes $=1$ and $\mathrm{No}=0$.

Religious belief was a binary variable. If the respondent believes in any particular religion, the answer was marked as 1 , otherwise we marked it with 0.

\subsection{Statistical Method}

Data were managed and analyzed with SPSS 17.0. First, we used descriptive statistics to assess the distribution of samples. Then we showed the prevalence of suicidal ideation according to each independent variable. T-tests or Chi-square tests were used to compare the difference on categorical and continuous variables across groups. Further, because the suicidal ideation was a binary variable, so we used the logistic regression to verify the association between independent variables and the dependent variables. We built three models to illustrate the results of the overall, the urban and the rural elderly respectively.

\section{Results}

\subsection{Basic Information of Samples}

The sample description and distribution are shown in Table 1 . The ages of the samples ranged from 60 to 103 and the average was 72.30 .

Table 1. Description of the Sample Characteristics.

\begin{tabular}{lccc}
\hline & \multicolumn{3}{c}{ Frequency (\%)/Mean (SD) } \\
\hline Variable & Overall & Urban & Rural \\
\hline$N$ & $18,683(100.00)$ & $9416(50.40)$ & $9267(49.60)$ \\
\hline Gender & & & \\
$\quad$ Male & $9608(51.43)$ & $4573(48.57)$ & $5035(54.33)$ \\
$\quad$ Female & $9075(48.57)$ & $4843(51.43)$ & $4232(45.67)$ \\
\hline Age & $72.30(7.457)$ & $72.33(7.228)$ & $72.27(7.684)$ \\
\hline Education level & & & \\
$\quad$ Illiteracy & $5413(28.97)$ & $1435(15.24)$ & $3978(42.93)$ \\
Primary school & $7260(38.86)$ & $3141(33.36)$ & $4119(44.45)$ \\
$\quad$ Junior high school or above & $6010(32.17)$ & $4840(51.40)$ & $1170(12.63)$ \\
\hline CCP membership & & & \\
$\quad$ Yes & $4163(22.28)$ & $3028(32.16)$ & $1135(12.25)$ \\
$\quad$ No & $14,520(77.72)$ & $6388(67.84)$ & $8132(87.75)$ \\
\hline Financial situation & & & \\
$\quad$ Sufficient & $215(1.15)$ & $123(1.31)$ & $92(0.99)$ \\
$\quad$ Relatively sufficient & $2152(11.52)$ & $1277(13.56)$ & $875(9.44)$ \\
Roughly enough & $10,762(57.60)$ & $6006(63.79)$ & $4756(51.32)$ \\
Relatively insufficient & $4338(23.22)$ & $1577(16.75)$ & $2761(29.79)$ \\
Insufficient & $1216(6.51)$ & $433(4.60)$ & $783(8.45)$ \\
\hline Marital status & & & \\
In marriage & $12,262(65.63)$ & $6520(69.24)$ & $5742(61.96)$ \\
Not in marriage & $6421(34.37)$ & $2896(30.76)$ & $3525(38.04)$ \\
\hline
\end{tabular}


Table 1. Cont.

\begin{tabular}{|c|c|c|c|}
\hline \multirow[b]{2}{*}{ Variable } & \multicolumn{3}{|c|}{ Frequency $(\%) /$ Mean (SD) } \\
\hline & Overall & Urban & Rural \\
\hline Number of children & $3.21(1.648)$ & $2.85(1.45)$ & $3.58(1.75)$ \\
\hline \multicolumn{4}{|l|}{ Chronic diseases } \\
\hline Yes & $14,400(77.08)$ & $7721(82.00)$ & $6679(72.07)$ \\
\hline No & $4283(22.92)$ & $1695(18.00)$ & $2588(27.93)$ \\
\hline \multicolumn{4}{|l|}{ Self-rated health status } \\
\hline Very unhealthy & $973(5.21)$ & 375 (3.98) & $598(6.45)$ \\
\hline Unhealthy & $3563(19.07)$ & $1434(15.23)$ & $2129(22.97)$ \\
\hline Average & $9810(52.51)$ & $5241(55.66)$ & 4569 (49.30) \\
\hline Healthy & $3643(19.50)$ & $2013(21.38)$ & $1630(17.59)$ \\
\hline Very healthy & $694(3.71)$ & $353(3.75)$ & $341(3.68)$ \\
\hline Disability of daily living & $1.33(0.440)$ & $1.28(0.420)$ & $1.37(0.460)$ \\
\hline Depression & $4.90(3.400)$ & $4.04(3.120)$ & $5.78(3.450)$ \\
\hline \multicolumn{4}{|l|}{ Visiting neighbors } \\
\hline Frequently & $5044(26.00)$ & $1912(20.31)$ & $3132(33.80)$ \\
\hline Occasionally & $8765(46.91)$ & $4346(46.16)$ & 4419 (47.69) \\
\hline Never & $4874(26.09)$ & $3158(33.54)$ & $1716(18.52)$ \\
\hline \multicolumn{4}{|l|}{ People who can help you } \\
\hline Yes & $16,873(90.31)$ & $8441(89.65)$ & $8432(90.99)$ \\
\hline No & $1810(9.69)$ & $975(10.35)$ & $835(9.01)$ \\
\hline \multicolumn{4}{|l|}{ Negative life events } \\
\hline Yes & $6863(36.73)$ & 3014 (32.01) & 3849 (41.53) \\
\hline No & $11,820(63.27)$ & $6402(67.99)$ & $5418(58.47)$ \\
\hline \multicolumn{4}{|l|}{ Religious belief } \\
\hline Yes & $2640(14.13)$ & $1412(15.00)$ & $1228(13.25)$ \\
\hline No & $16,043(85.87)$ & $8004(85.00)$ & 8039 (86.75) \\
\hline
\end{tabular}

\subsection{Prevalence of Suicidal Ideation}

The prevalence of suicidal ideation among the Chinese Elderly was revealed in Table 2. The prevalence of Suicidal ideation among the overall elderly was $2.77 \%$. As Figure 1 showed, the female elderly in rural areas had the highest prevalence of suicidal ideation, up to $4.18 \%$, while the male elderly in urban areas had the lowest prevalence of suicidal ideation, which was only $1.68 \%$. The suicidal ideation was statistically significant between rural and urban regions $\left(\chi^{2}=41.495\right.$, $p<0.001)$.

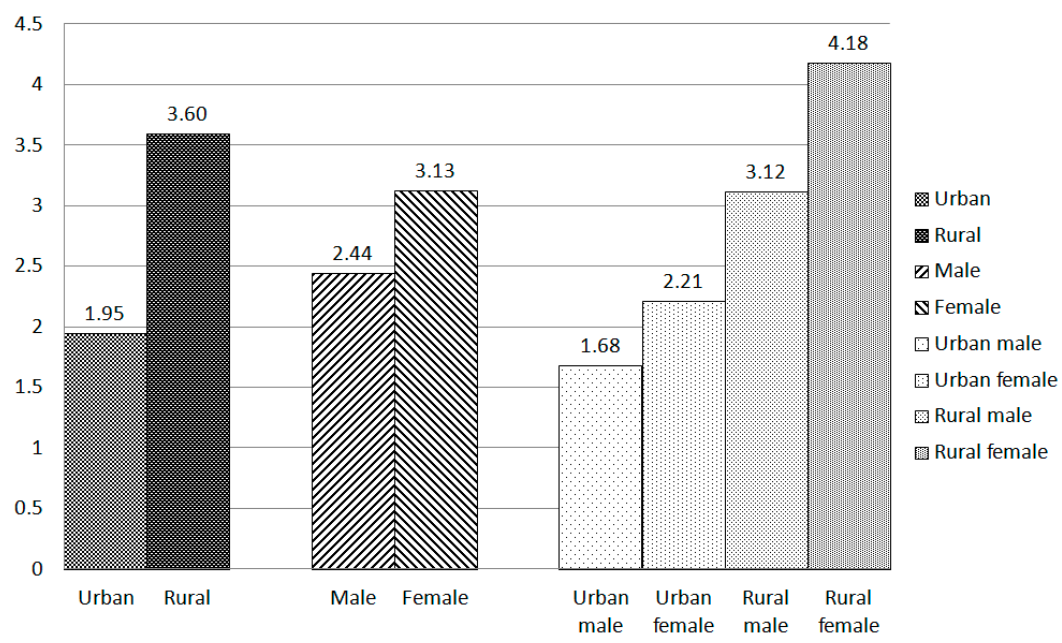

Figure 1. Prevalence of suicidal ideation among Urban and rural elderly (\%). 
Table 2. Prevalence of Suicidal ideation among the Chinese Elderly.

\begin{tabular}{|c|c|c|c|c|c|c|}
\hline \multirow[b]{2}{*}{ Variable } & \multicolumn{2}{|c|}{ Overall } & \multicolumn{2}{|c|}{ Urban } & \multicolumn{2}{|c|}{ Rural } \\
\hline & $\%$ & $p$ & $\%$ & $p$ & $\%$ & $p$ \\
\hline Overall & 2.77 & & 1.95 & & 3.60 & \\
\hline Gender & & 0.004 & & 0.066 & & 0.006 \\
\hline Male & 2.44 & & 1.68 & & 3.12 & \\
\hline Female & 3.13 & & 2.21 & & 4.18 & \\
\hline Age & - & 0.000 & - & 0.000 & - & 0.000 \\
\hline Education level & & 0.000 & & 0.000 & & 0.000 \\
\hline Illiteracy & 4.67 & & 4.04 & & 4.90 & \\
\hline Primary school & 2.42 & & 2.01 & & 2.74 & \\
\hline Junior high school or above & 1.48 & & 1.95 & & 2.22 & \\
\hline CCP membership & & 0.000 & & 0.004 & & 0.002 \\
\hline Yes & 1.54 & & 1.35 & & 2.03 & \\
\hline No & 3.13 & & 2.24 & & 3.82 & \\
\hline Financial situation & & 0.000 & & 0.000 & & 0.000 \\
\hline Sufficient & 0.93 & & 0.00 & & 2.17 & \\
\hline Relatively sufficient & 0.93 & & 0.94 & & 0.91 & \\
\hline Roughly enough & 1.33 & & 1.08 & & 1.64 & \\
\hline Relatively insufficient & 5.30 & & 4.31 & & 5.87 & \\
\hline Insufficient & 10.12 & & 9.01 & & 10.73 & \\
\hline Marital status & & 0.000 & & 0.002 & & 0.000 \\
\hline In marriage & 2.27 & & 1.66 & & 2.96 & \\
\hline Not in marriage & 3.74 & & 2.62 & & 4.65 & \\
\hline Number of children & & 0.000 & & 0.001 & & 0.024 \\
\hline Chronic diseases & & 0.000 & & 0.000 & & 0.000 \\
\hline Yes & 3.32 & & 2.25 & & 4.55 & \\
\hline No & 0.93 & & 0.59 & & 1.16 & \\
\hline Self-rated health status & & 0.000 & & 0.000 & & 0.000 \\
\hline Very unhealthy & 11.92 & & 13.07 & & 11.20 & \\
\hline Unhealthy & 6.01 & & 4.32 & & 7.14 & \\
\hline Average & 1.51 & & 1.09 & & 1.99 & \\
\hline Healthy & 0.96 & & 0.70 & & 1.29 & \\
\hline Very healthy & 0.72 & & 0.57 & & 0.88 & \\
\hline Disability of daily living & & 0.000 & & 0.000 & & 0.000 \\
\hline Depression & & 0.000 & & 0.000 & & 0.000 \\
\hline Visiting neighbors & & 0.000 & & 0.000 & & 0.000 \\
\hline Frequently & 2.24 & & 1.88 & & 2.46 & \\
\hline Occasionally & 2.21 & & 1.27 & & 3.15 & \\
\hline Never & 4.33 & & 2.94 & & 6.88 & \\
\hline People who can help you & & 0.000 & & 0.000 & & 0.000 \\
\hline Yes & 2.41 & & 1.72 & & 3.10 & \\
\hline No & 6.19 & & 4.00 & & 8.74 & \\
\hline Negative life events & & 0.000 & & 0.000 & & 0.000 \\
\hline Yes & 4.30 & & 3.68 & & 4.78 & \\
\hline No & 1.89 & & 1.14 & & 2.77 & \\
\hline Religious belief & & 0.000 & & 0.080 & & 0.000 \\
\hline Yes & 3.94 & & 2.55 & & 5.54 & \\
\hline No & 2.58 & & 1.85 & & 3.31 & \\
\hline
\end{tabular}

\subsection{Logistic Analysis about the Suicide Ideation in Chinese Elderly}

In order to discuss the explanatory power of the factors above, we put all the independent variables into the regression model. Specific information is shown in Table 3. According to the results of the logistic regression, gender, education level, political affiliation, marital status and self-rated 
health status were not statistically significantly associated with suicidal ideation but several variables did. What is more, the factors were different among urban and rural elderly.

Table 3. Logistic Regression of the prevalence of Suicidal Ideation.

\begin{tabular}{|c|c|c|c|c|c|c|}
\hline \multirow[b]{2}{*}{ Variable } & \multicolumn{2}{|c|}{ Model 1-Overall } & \multicolumn{2}{|c|}{ Model 2-Urban } & \multicolumn{2}{|c|}{ Model 3-Rural } \\
\hline & OR & $p$ & OR & $p$ & OR & $p$ \\
\hline Gender (Male) & 1.055 & 0.619 & 1.113 & 0.566 & 1.019 & 0.887 \\
\hline Age & 1.002 & 0.811 & 1.026 & 0.046 & 0.990 & 0.276 \\
\hline \multicolumn{7}{|c|}{ Education level (Ref. = junior high school or above) } \\
\hline Primary school & 0.863 & 0.315 & 0.877 & 0.516 & 0.869 & 0.546 \\
\hline Illiteracy & 1.057 & 0.728 & 1.049 & 0.842 & 1.070 & 0.775 \\
\hline CCP membership (Yes) & 1.032 & 0.837 & 1.212 & 0.363 & 0.817 & 0.388 \\
\hline \multicolumn{7}{|c|}{ Financial situation (Ref. = insufficient) } \\
\hline Relatively insufficient & 0.921 & 0.522 & 0.922 & 0.732 & 0.908 & 0.535 \\
\hline Roughly enough & 0.501 & 0.000 & 0.546 & 0.018 & 0.466 & 0.000 \\
\hline Relatively sufficient & 0.495 & 0.009 & 0.620 & 0.220 & 0.371 & 0.012 \\
\hline Sufficient & 0.419 & 0.235 & 0.000 & 0.996 & 0.677 & 0.602 \\
\hline Marital status (Yes) & 1.195 & 0.102 & 1.431 & 0.062 & 1.056 & 0.686 \\
\hline Number of children & 1.073 & 0.010 & 1.048 & 0.371 & 1.085 & 0.012 \\
\hline Chronic diseases (Yes) & 2.000 & 0.000 & 1.650 & 0.154 & 2.158 & 0.000 \\
\hline \multicolumn{7}{|c|}{ Self-rated health status (Ref. = very healthy) } \\
\hline Healthy & 1.037 & 0.940 & 0.756 & 0.715 & 1.228 & 0.745 \\
\hline Average & 0.777 & 0.589 & 0.570 & 0.447 & 0.932 & 0.907 \\
\hline Unhealthy & 1.143 & 0.778 & 0.807 & 0.777 & 1.380 & 0.597 \\
\hline Very unhealthy & 1.167 & 0.753 & 1.278 & 0.754 & 1.110 & 0.869 \\
\hline Disability of daily living & 1.602 & 0.000 & 1.305 & 0.140 & 1.726 & 0.000 \\
\hline Depression & 1.302 & 0.000 & 1.338 & 0.000 & 1.280 & 0.000 \\
\hline \multicolumn{7}{|c|}{ Visiting neighbors (Ref. = never) } \\
\hline Occasionally & 0.666 & 0.000 & 0.648 & 0.019 & 0.650 & 0.002 \\
\hline Frequently & 0.930 & 0.591 & 1.352 & 0.174 & 0.767 & 0.118 \\
\hline People who can help you & 0.550 & 0.000 & 0.559 & 0.004 & 0.555 & 0.000 \\
\hline Influence of major events & 1.095 & 0.362 & 1.412 & 0.045 & 0.952 & 0.692 \\
\hline Religious belief & 1.462 & 0.002 & 1.118 & 0.588 & 1.708 & 0.000 \\
\hline Location (Rural) & 1.084 & 0.471 & & & & \\
\hline Constant & 0.002 & 0.000 & 0.000 & 0.000 & 0.005 & 0.000 \\
\hline Nagelkerke $\mathrm{R}^{2}$ & 0.2282 & & 0.2557 & & 0.2400 & \\
\hline
\end{tabular}

\section{Conclusions}

\subsection{Main Findings of This Study}

We found that age, social economic status, family factors, physical health, mental health, living ability, social interaction and religious belief did have effects on the prevalence of suicidal ideation. Household income and expenditure, the number of children, chronic diseases, disability in daily living, depression and social interaction had influence on both the urban and rural elderly. Better conditions of household income and expenditure will decrease the level of suicidal ideation. The elderly who have more children tend to have a higher level of suicidal ideation than those who have fewer or no children, which is especially true of the rural elderly. This can be explained with the Strain Theory of Suicide and mental disorder [21,22]. In rural China today with the fast growing economy, the elderly remain traditional in social values while the youth have started move away from the traditional Confucianism, which may create psychological strains for the elderly due to the discrepancy between their expectation of their children's filial piety and the reality. Healthier old people and the elderly 
who can manage their daily living are less likely to think about suicide [8,23]. The level of depression is also a conspicuous factor [24].

However, several variables influencing the prevalence of suicidal ideation among rural and urban elderly were different. One of the important reasons is the large social environmental gap between rural and urban regions in China [25]. Among the urban elderly, age had a positive effect on the prevalence of suicidal ideation [26]. Among the rural elderly, religious belief had a positive effect on the prevalence of suicidal ideation, which has been identified in many previous studies in China [27].

\subsection{What Is Already Known on This Topic and What This Study Has Added}

Elderly populations are usually at a higher risk of suicide and mental problems in most societies, which is consistent with our results in the urban region [28,29]. We have explored in this study the influencing factors on the suicidal ideation among the Chinese elderly and found some risk factors especially in Chinese culture and certain differences between rural and urban elderly. These findings can be the basis for our future study as well as for policy-making in the efforts to reduce suicide among the elderly in China. In general, the prevalence of suicidal ideation in China might be a reflection of the social and economic transformation in the past few decades in the developing country. For example, the fast-growing economy brings about a cultural change in China. As society becomes industrialized from farming environments, modernized from traditional ideology and urbanized from a rural life style, younger generations are more likely to give up the traditional life and traditional social values than the elderly, while the latter still uphold traditional values such as Confucianism. One of the major teachings of Confucianism is filial piety, the veneration of the elderly by the children. While the Chinese elderly still hold the traditional values as important and as their expectation for their children, the younger generation are far more modernized than their parents and grandparents. This discrepancy between the elderly's traditional aspirations and their children's beliefs and behaviors can create some type of psychological strains among the elderly, which may make them feel frustrated, helpless, angered, or suicidal [21].

\subsection{Limitations of This Study}

Due to the limitations of the data and the research design, there may still be some important factors that were not considered in the relationship to Chinese elderly suicidal ideation. Besides, as the cultural differences in the China and Western countries, many correlates which have been supported in previous studies were not found in the current study [30]. We need to do further cross-cultural research on elderly psychopathologies and suicidal ideation.

Author Contributions: Jianwen Wei conceptualized the paper and revised the manuscript; Jie Zhang conceived and designed the study and finalized the final paper; Yuping Deng performed the data analyses and wrote the first draft of the paper; Long Sun provided statistical expertise and Ping Guo designed the survey and collected the data.

Conflicts of Interest: The authors declare no conflict of interest. The founding sponsors had no role in the design of the study; in the collection, analyses, or interpretation of data; in the writing of the manuscript and in the decision to publish the results.

\section{References}

1. National Bureau of Statistics of China (NBS). 2010 Sixth National Population Census Data Gazette (No. 1); National Census Bureau: Beijing, China, 2011.

2. Zhang, J.; Jing, J.; Wu, X.; Sun, W.; Wang, C. A Sociological Analysis of the Decline in the Suicide Rate in China. Soc. Sci. China 2011, 2011, 97-113.

3. Li, X.; Xiao, Z.; Xiao, S. Suicide among the elderly in mainland China. Psychogeriatrics 2009, 9, 62-66. [CrossRef] [PubMed]

4. Yip, P.S.; Liu, K.Y.; Hu, J.; Song, X.M. Suicide rates in China during a decade of rapid social changes. Soc. Psychiatry Psychiatr. Epidemiol. 2005, 40, 792-798. [CrossRef] [PubMed] 
5. Crawford, M.J.; Nur, U.; McKenzie, K.; Tyrer, P. Suicidal Ideation and Suicide Attempts among Ethnic Minority Groups in England: Results of a National Household Survey. Psychol. Med. 2005, 35, 1369-1377. [CrossRef] [PubMed]

6. Lyons, M.J. Observable and subjective factors associated with attempted suicide in later life. Suicide Life Threat Behav. 1985, 15, 168-183. [CrossRef] [PubMed]

7. Conwell, Y.; Duberstein, P.R. Suicide in elders. Ann. N. Y. Acad. Sci. 2001, 932, 132-147, discussion 47-50. [CrossRef] [PubMed]

8. Dennis, M.S.; Wakefield, P.; Molloy, C.; Andrews, H.; Friedman, T. A study of self-harm in older people: Mental disorder, social factors and motives. Aging Ment. Health 2007, 11, 520-525. [CrossRef] [PubMed]

9. Aziz, R.; Steffens, D.C. What are the causes of late-life depression? Psychiatr. Clin. N. Am. 2013, 36, 497-516. [CrossRef] [PubMed]

10. Handley, T.E.; Hiles, S.A.; Inder, K.J.; Kay-Lambkin, F.J.; Kelly, B.J.; Lewin, T.J.; McEvoy, M.; Peel, R.; Attia, J.R. Predictors of Suicidal Ideation in Older People: A Decision Tree Analysis. Am. J. Geriatr. Psychiatry 2013, 22, 1325-1335. [CrossRef] [PubMed]

11. Ismail, Z.; Fischer, C.; McCall, W.V. What characterizes late-life depression? Psychiatr. Clin. N. Am. 2013, 36, 483-496. [CrossRef] [PubMed]

12. Fassberg, M.M.; van Orden, K.A.; Duberstein, P.; Erlangsen, A.; Lapierre, S.; Bodner, E.; Canetto, S.S.; De Leo, D.; Szanto, K.; Waern, M. A systematic review of social factors and suicidal behavior in older adulthood. Int. J. Environ. Res. Public Health 2012, 9, 722-745. [CrossRef] [PubMed]

13. Vanderhorst, R.K.; McLaren, S. Social relationships as predictors of depression and suicidal ideation in older adults. Aging Ment. Health 2005, 9, 517-525. [CrossRef] [PubMed]

14. Kang, H.J.; Stewart, R.; Jeong, B.O.; Kim, S.Y.; Bae, K.Y.; Kim, S.W.; Kim, J.M.; Shin, I.S.; Yoon, J.S. Suicidal ideation in elderly Korean population: A two-year longitudinal study. Int. Psychogeriatr. 2014, 26, 59-67. [CrossRef] [PubMed]

15. Kinyanda, E.; Hjelmeland, H.; Musisi, S. Negative life events associated with deliberate self-harm in an African population in Uganda. Crisis 2005, 26, 4-11. [CrossRef] [PubMed]

16. Almeida, O.P.; Draper, B.; Snowdon, J.; Lautenschlager, N.T.; Pirkis, J.; Byrne, G.; Sim, M.; Stocks, N.; Flicker, L.; Pfaff, J.J. Factors associated with suicidal thoughts in a large community study of older adults. Br. J. Psychiatry 2012, 201, 466-472. [CrossRef] [PubMed]

17. Guo, P. A Study of Sampling and Weighting Procedures for Sample Survey of the Aged Population in Urban/Rural China (2000, 2006 \& 2010). Popul. Dev. 2013, 19, 77-84.

18. Tang, D. Application of Short Form Geriatric Depression Scale (GDS-15) in Chinese Elderly. Chin. J. Clin. Psychol. 2013, 21, 402-405.

19. He, X.; Xiao, S.; Zhang, D. Reliability and Validity of the Chinese Version of Geriatric Depression Scale: A Study in A Population of Chinese Rural Community-dwelling Elderly. Chin. J. Clin. Psychol. 2008, 16, 473-475.

20. Mei, J. Reliability and Validity of GDS and GHQ short form for the aged. Chin. J. Psychiatry 1999, 32, 41-43.

21. Zhang, J.; Wieczorek, W.F.; Conwell, Y.; Tu, X.M. Psychological strains and youth suicide in rural China. Soc. Sci. Med. 2011, 72, 2003-2010. [CrossRef] [PubMed]

22. Zhang, J.; Wieczorek, W.F.; Conwell, Y.; Tu, X.M.; Wu, B.Y.W.; Xiao, S.; Jia, C. Characteristics of young rural Chinese suicides: A psychological autopsy study. Psychol. Med. 2010, 40, 581-589. [CrossRef] [PubMed]

23. Conwell, Y.; Duberstein, P.R.; Caine, E.D. Risk factors for suicide in later life. Biol. Psychiatry 2002, 52, 193-204. [CrossRef]

24. Mitty, E.; Flores, S. Suicide in Late Life. Geriatr. Nurs. (Lond.) 2008, 29, 160-165. [CrossRef] [PubMed]

25. Read, J.M.; Lessler, J.; Riley, S.; Wang, S.; Tan, L.J.; Kwok, K.O.; Guan, Y.; Jiang, C.Q.; Cummings, D.A. Social mixing patterns in rural and urban areas of southern China. Proc. Biol. Sci. 2014, 281, 20140268. [CrossRef] [PubMed]

26. Wang, Z.; Koenig Harold, G.; Ma, W.; Liu, L. Religious Involvement, Suicidal Ideation and Behavior in Mainland China. Int. J. Psychiatry Med. 2015, 48, 299-316. [CrossRef] [PubMed]

27. Jing, J.; Zhang, J.; Wu, X. Suicide among the Elderly People in Urban China. Popul. Res. 2011, 35, 84-96.

28. Wang, C.-W.; Chan, C.L.W.; Yip, P.S.F. Suicide rates in China from 2002 to 2011: An update. Soc. Psychiatry Psychiatry Epidemiol. 2013. [CrossRef] [PubMed] 
29. Beck, A.T.; Steer, R.A.; Kovacs, M.; Garrison, B. Hopelessness and eventual suicide: A 10-year prospective study of patients hospitalized with suicidal ideation. Am. J. Psychiatry 1985, 142, 559-563. [PubMed]

30. Zhang, J.; Eric, Y.L. The Confucian Ethic of Female Subordination and Depression among Young People in Rural China. Interdiscip. J. Res. Relig. 2012, 8, 3. 